THE COVID PANDEMIC AND MIGRANTS: A TEN POINT AGENDA TO

MITIGATE THE ONGOING DISASTER

\title{
LA PANDEMIA DE COVID Y LOS MIGRANTES: UNA AGENDA DE DIEZ PUNTOS PARA MITIGAR EL DESASTRE EN CURSO
}

\author{
Patrick Taran ${ }^{1}$, Nayeth Idalid Solorzano Alcivar ${ }^{2}$
}

\section{Palabras clave: \\ Migrantes, \\ Refugiados, \\ Asilados, \\ Apátridas, \\ COVID-19, \\ Derechos- \\ Humanos, \\ Migración, \\ Legislación, \\ Discriminación, \\ Políticas}

\section{Resumen}

A nivel mundial, millones de migrantes, refugiados, solicitantes de asilo y apátridas se encuentran entre los más afectados por la pandemia de COVID-19. Millones más de migrantes estacionales e itinerantes se ven afectados de manera similar. No obstante, incluso durante los bloqueos más severos, muchos países siguen dependiendo de los migrantes y refugiados para realizar trabajos esenciales como mantener en funcionamiento los servicios de salud, la producción de alimentos, la industria, el comercio y otros sectores. Se argumenta que las respuestas efectivas a la pandemia de coronavirus, en particular aquellas enfocadas en migrantes y refugiados, deben respetar los derechos, ser apropiadas y proporcionadas para prevenir la propagación de COVID y garantizar la capacidad de las personas - y las economías - para mantener la situación social, local y bienestar nacional. Sin embargo, muchas políticas y acciones que abordan el COVID-19 se han implementado con poca o ninguna consideración por los migrantes y refugiados. Esto ha resultado en problemas de salud, mortalidad, desempleo, prevención de COVID y tratamientos, deportación masiva y pérdida de medios de vida para estas poblaciones. Siguiendo un análisis crítico, en esta investigación se identifican diez temas que caracterizan una respuesta integradora e integral dirigida a migrantes y refugiados. Las soluciones rápidas desvían recursos, mientras que solo un conjunto de respuestas que abordan los problemas interrelacionados de salud, protección social, empleo, comunidad, género, movilidad transfronteriza, no discriminación, comunicación y recuperación, pueden resolver los desafíos planteados por la pandemia en este mundo móvil e interdependiente.

Códigos JEL: F22, J15, J61

\footnotetext{
${ }^{1}$ Global Migration Policy Associates - GMPA, Ginebra, Suiza.

E-mail: taran@globalmigrationpolicy.org

${ }^{2}$ Escuela Superior Politécnica del Litoral - ESPOL, Guayaquil, Ecuador.

E-mail: nsolorza@espol.edu.ec
} 


\begin{abstract}
Keywords:

Globally, millions of migrants, refugees, asylum-seekers, and

Migrants, stateless persons are among those most affected by the COVID-19 pandemic. Millions more seasonal and itinerant migrants are Refugees, Asylees, Stateless, COVID-19, Human rights, Migration, Legislation, Discrimination, Policies similarly affected. Nonetheless, even during the most severe lockdowns, many countries remain dependent on migrants and refugees to do essential work to keep health services, food production, industry, commerce, and other sectors operating. It is argued that effective responses to the coronavirus pandemic, notably those focused on migrants and refugees, must respect rights, be appropriate and proportionate to prevent the spread of COVID, and guarantee the ability of people - and economies - to maintain social, local, and national well-being. However, many policies and actions addressing COVID-19 have been implemented with little or no consideration for migrants and refugees, resulting in health issues, mortality rates, unemployment, COVID prevention, treatment, and mass deportation loss of livelihood for populations. Following a critical analysis, this research identifies ten themes characterizing an integrated, comprehensive response addressing migrants and refugees. Quick fixes divert resources, while only a set of responses addressing the interrelated issues of health, social protection, employment, community, gender, cross-border mobility, nondiscrimination, communication, and recovery can solve challenges posed by the pandemic in this mobile and interdependent world.

JEL Codes: F22, J15, J61
\end{abstract}

\section{INTRODUCCIÓN ${ }^{3}$}

A nivel mundial, decenas de millones de migrantes, refugiados, solicitantes de asilo (asilados) y apátridas (MRAA), se encuentran entre los más afectados por la pandemia de COVID-19. Esto incluye también a millones de migrantes estacionales e itinerantes se ven afectados de manera similar. No obstante, se conoce que incluso durante los bloqueos más severos, muchos países siguen dependiendo de los migrantes y refugiados para realizar trabajos esenciales como mantener en funcionamiento los servicios de salud, la producción de alimentos, la industria, el comercio, el transporte, entre otros sectores.
En general, el movimiento de personas a través de las fronteras sigue siendo un salvavidas incomprendido y subestimado para países y pueblos de todo el mundo. De hecho, la mayoría de los países industrializados y muchos países en desarrollo, dependen de trabajadores migrantes, nacidos en el extranjero. Por región, los trabajadores migrantes son 41 por ciento del total de la mano de obra en los países Árabes, 20.6 por ciento en Norte-América, 18 por ciento en Europa del Norte, del Oeste y del Sur, 9 por ciento en el Este Europeo, y 11 por ciento en el Oeste Asiático (ILO, 2019). También se indica que, a mediados del 2020, más de 26,3 millones de refugiados deben su seguridad y supervivencia al hecho de haber cruzado las fronteras para protegerse de la persecución, la guerra y las violaciones de los derechos humanos (UNHCR, 2020a).

\footnotetext{
$3 \mathrm{El}$ alcance de este informe incluye a los solicitantes de asilo y apátridas, y también se refiere como relevante a los desplazados internos (PDI) y otras personas desplazadas, cuyas situaciones y tratamiento en el contexto de la pandemia de COVID-19 son a menudo similares a las de refugiados y trabajadores migrantes y miembros de su familia.
} 
Sin embargo, y a pesar de estos precedentes sobre la problemática migratoria, muchas políticas y acciones que abordan el COVID-19 se han implementado con poca o ninguna consideración para los migrantes y refugiados. Como consecuencia, esta falta de acciones y políticas ha resultado en problemas de salud, mortalidad, desempleo, tratamientos y prevención de COVID, deportaciones masivas y pérdida de medios de vida para estas poblaciones. Como se demostró en algunos países, las medidas de COVID-19 o la falta de ellas, agravan los riesgos de propagar el virus e impedir la recuperación económica y social.

Los estándares normativos internacionales, el amplio conocimiento científico y la experiencia probada proporcionan la base para generar respuestas efectivas a la pandemia del COVID19. Se discute que estas respuestas deben respetar los derechos, ser apropiadas y proporcionadas para prevenir la propagación de COVID y garantizar la capacidad de las personas y las economías para mantener la situación social, local y bienestar nacional.

Siguiendo un análisis crítico, se identifican diez temas que caracterizan una respuesta integradora $\mathrm{e}$ integral dirigida a migrantes $\mathrm{y}$ refugiados, también aplicables para los apátridas. Evidencias sobre el estudio realizado revelan que sólo un conjunto de respuestas que abordan los problemas interrelacionados de salud, protección social, empleo, comunidad, género, movilidad transfronteriza, no discriminación, comunicación y recuperación, pueden resolver los desafíos planteados por la pandemia en este mundo móvil e interdependiente.

\section{METODOLOGIA}

La metodología aplicada se enfoca en el análisis crítico de fuentes primarias y secundarias y formulación de acciones que sintetizan en cuatro ejes: 1) una revisión extensiva de datos e informes sobre el impacto y efecto de COVID en refugiados y migrantes, principalmente informes $\mathrm{y}$ estudios institucionales junto con noticias de prensa; 2) una revisión y compilación de recomendaciones de acciones sobre líneas de respuestas emitidas por organizaciones internacionales especializadas y competentes en materias relevantes, 3) una identificación de acciones relevantes de parlamentos y parlamentaríamos en todas las regiones, y 4) la elaboración de una guía integral marco de referencia. La elaboración de las líneas de orientación toma en cuenta particularmente las recomendaciones emitidas por la Agencia de la Organización de Naciones Unidas (ONU) para los Refugiados (ACNUR), la Organización Internacional de Migración (OIM), la Organización Internacional del Trabajo (OIT), la Organización Mundial de la Salud (OMS) y la Entidad de las Naciones Unidas para la Igualdad de Género y el Empoderamiento de la Mujer (UNWOMEN). Una verificación inicial fue concretamente la identificación de las recomendaciones y las acciones de instancias parlamentarias.

El esquema de la guía marco que se propone está basada e inspirada en la guía 'Promoting a Rights-based Approach to Migration, Health, HIV and AIDS: A Framework for Action' (Promoviendo un enfoque de la migración, la salud y el VIH-SIDA basado en los derechos: un marco de acción), publicada por la OIT (ILO, 2017) . Las investigaciones también se apoyaron en los 45 años de experiencia profesional del investigador principal en campos de migraciones, refugiados, salud, legislación, políticas a niveles locales, nacionales y globales en varias regiones del mundo, particularmente África, las Américas y Europa.

\section{ANALISIS CRITICO Y RESULTADOS}

\section{Desafíos a los que se enfrentan los refugiados, los migrantes, y las comunidades de acogida y los países de residencia}

Según el ACNUR, más de 134 países que acogen a refugiados se han visto afectados por la pandemia de COVID-19 y el $85 \%$ de los refugiados del mundo están alojados en países en desarrollo (UNHCR, 2021). Se conoce también que decenas de millones de MRAA, desplazados internos y migrantes temporales en todo el mundo se encuentran entre los más gravemente afectados por la pandemia COVID-19 y que, a pesar de ello, mayoría de los países siguen dependiendo de 
muchos de ellos en trabajo esenciales dentro de los servicios de mantenimiento en variados sectores, incluso durante los meses de bloqueos más severos. Sin embargo, muchas de las políticas $\mathrm{y}$ acciones que abordan el COVID-19 se han tomado con poca o ninguna consideración para este tipo de población.

Excluir a estos grupos poblacionales en riesgo, como parte innegable de una sociedad, trae consigo consecuencias nefastas en respuestas de recuperación de una nación contra la pandemia actual. Esta repercusión, no sólo afecta a estas poblaciones, sino en general a las condiciones humanas, sanitarias, sociales y económicas de las comunidades de acogida en los países de residencia y los países de origen.

Se puede identificar como las más graves a las medidas formales o informales, intencionales o no, que en diferentes grados en y diferentes situaciones excluyen a los extranjeros y MRAA como grupos de personas desplazadas de la atención médica y de la prevención, las pruebas y el tratamiento del coronavirus. Dichas medidas van desde restricciones "solo para ciudadanos", hasta la aplicación del control de inmigración, lo que deja a los migrantes y refugiados, en particular aquellos en situación irregular o con permisos no extendidos, temerosos de acudir a los proveedores de atención médica debido a la falta de documentación y el temor a la discriminación o deportación. Esta problemática ha traído como consecuencia la deportación de personas portadoras de COVID, ya sea por detención o despido sin ser notificados.

La exclusión también se debe a interrupciones en el funcionamiento de los sistemas de Registro Civil y Estadísticas Vitales (CRVS), entre otros servicios de documentación, como la emisión de tarjetas de identificación nacionales o extensión de permisos para extranjeros que no pueden salir debido a restricciones o situaciones de viajes internacionales en los países de origen. En general, la exclusión de los trabajadores y empresarios migrantes y refugiados, así como de los solicitantes de asilo, los desplazados internos y los apátridas de las medidas de estímulo económico sigue siendo generalizada, lo cual frustra la inclusión de todo lo necesario para la recuperación sostenible y la reconstrucción de las economías.

Las medidas ampliamente impuestas incluyeron el cierre de fronteras y la detención o restricción del movimiento de migrantes, así como de refugiados, solicitantes de asilo y apátridas. Esto, a pesar de las consecuencias adversas para la producción de alimentos, el trabajo de salud, el cuidado de ancianos y niños, el transporte $\mathrm{y}$ otros trabajos esenciales para apoyar la recuperación contra la pandemia, incluyendo también la protección de los refugiados. Existen, por ejemplo, medidas de cierre que dejaron a los MRAA y desplazados internos, muy expuestos a la infección y la transmisión; reteniendo a los trabajadores extranjeros en "trabajos esenciales" pero con poco o ningún equipo de protección personal (EPP), expuestos a situaciones laborales y de vida de alto riesgo. También se registraron expulsiones y deportaciones de territorios de extranjeros, incluidos vuelos de deportación a sus países de origen a pesar del cierre de los viajes aéreos y el riesgo de devolución de refugiados y solicitantes de asilo.

Como consecuencia a esta medidas, se registraron: ausencia de personal de salud, altas tasas de infección y muerte entre los trabajadores de salud inmigrantes, migrantes y refugiados; reducción de la producción de alimentos debido a la ausencia de trabajadores migrantes para actividades cruciales de siembra, cultivo, cosecha $\mathrm{y}$ procesamiento para las cuales el recurso humano local y nativo muchas veces no está disponible; y limitaciones en el transporte donde muchos conductores de camiones, autobuses y ferrocarriles son migrantes y operan a nivel internacional.

Los costos económicos y las limitaciones afectaron y continúan debilitando sectores enteros de economías en países de África, Eurasia, Europa y las Américas que dependen de la movilidad internacional de personas para proporcionar mano de obra y habilidades. El trabajo agrícola estacional, la producción de alimentos, la atención de la salud, la construcción, la producción y comercialización industrial local o regional, la distribución de bienes y servicios se 
encuentran entre los numerosos sectores esenciales afectados negativamente en muchos países.

Además, los trabajadores informales y las mujeres en países con disposiciones discriminatorias de género en las leyes de nacionalidad se encuentran en una situación de riesgos exacerbados. En muchos países de acogida, los refugiados y las personas desplazadas por la fuerza a menudo dependen de la economía informal, y han sido de los primeros en sentir el impacto económico de los bloqueos. Muchos han perdido sus trabajos, han sido desalojados de sus hogares y sus hijos han estado fuera de la escuela durante muchos meses debido a los impactos socioeconómicos del COVID-19. Aquellos que continúan trabajando a menudo tienen acceso limitado a equipo de protección personal (EPP) y están expuestos al riesgo de infectarse por COVID-19.

Por otro lado, veinticinco países todavía tienen disposiciones discriminatorias de género en sus leyes de nacionalidad que niegan a las mujeres los mismos derechos que a los hombres para conferir la nacionalidad a sus hijos. Al menos cincuenta países niegan a mujeres y hombres los mismos derechos para conferir la nacionalidad a sus cónyuges no ciudadanos (Global-Campaign, 2021). Ambos tipos de discriminación de género pueden conducir a la apatridia y, a menudo, hacer que los familiares de las ciudadanas de estos países tengan que recurrir a visas para residir legalmente en el país de su madre o cónyuge. En consecuencia, estos niños nacidos en el país comparten los riesgos que enfrentan los padres inmigrantes y refugiados de la exclusión de la atención médica, los esfuerzos de prevención y mitigación de COVID. También en algunos casos se los excluye de la asistencia económica, el apoyo nutricional básico y el "estímulo" necesario para una vida digna, o hasta para la supervivencia.

Se han reportado situaciones especialmente graves para los trabajadores migrantes en Oriente Medio y países del Golfo, así también en países de Asia, África, Eurasia, Europa, América del Norte y del Sur y la región del Pacífico. Literalmente, millones de trabajadores migrantes fueron despedidos arbitraria e inmediatamente del trabajo en la región de Oriente Medio y en otros lugares. En algunos países, los migrantes fueron expulsados físicamente $\mathrm{u}$ obligados a abandonar ciudades o lugares donde vivían y trabajaban. Se establecieron cuarentenas forzadas drásticas, como "sellar" vecindarios de migrantes, residencias / residencias de migrantes y / o áreas industriales, así como campamentos de refugiados y desplazados internos (Business-andHuman-Rights-Resource-Center, 2020).

Los informes de grupos de monitoreo de derechos humanos sobre situaciones en varios países describieron condiciones nuevas y preexistentes que enfrentan los MRAA y personas desplazadas por la fuerza en todo el mundo que han sido exacerbadas por el COVID-19. Como se expresa en un informe nacional de un organismo de vigilancia de los derechos humanos, "los trabajadores migrantes se enfrentan a una serie de abusos arraigados por parte de los empleadores, que incluyen prácticas de contratación engañosas, robo de salarios, confiscación de pasaportes, condiciones de vida y de trabajo inseguras y demandas laborales excesivas, que indican trabajo forzoso y violan las normas nacionales e internacionales. La propagación del Covid-19 y el cierre para contenerlo ha exacerbado estas condiciones, ya que los trabajadores enfrentan la pérdida de empleo, licencias sin goce de sueldo, salarios reducidos y trabajo forzoso sin paga" (Human-Rights-Watch, 2020a) .

Los migrantes y otras personas presuntamente extranjeras también se han enfrentado a una violencia mortal. Por ejemplo, en agosto de 2020 surgieron informes de docenas de migrantes africanos que habían recibido disparos a ambos lados de una frontera en el Medio Oriente en abril, con los temores de COVID 19 citados como pretexto (Human-Rights-Watch, 2020b) . Los informes de noticias y los organismos de vigilancia han reportado aumentos en los ataques violentos, algunos mortales, contra personas de apariencia china u otra asiática en África, América y Europa (Human-Rights-Watch, 2020c). Las oficinas del ACNUR también informaron de un aumento de los incidentes de discriminación, estigmatización y xenofobia contra refugiados y personas desplazadas, lo que 
agravó aún más las tensiones con las comunidades locales. Los bloqueos y el aumento de las tensiones familiares también han provocado picos de violencia de género en todo el mundo (UNCHR, 2020b).

\section{Refugiados, desplazados internos, apátridas y solicitantes de asilo}

Los refugiados, solicitantes de asilo, desplazados internos y apátridas, especialmente aquellos que se encuentran en situaciones de campamentos abarrotados, con condiciones sanitarias e higiénicas nefastas e imposibilidad de distanciamiento social, corren un riesgo especial de infección por coronavirus. Los principales desafíos incluyen: la falta de atención médica, alimentos insuficientes, viviendas atiborradas, falta de agua corriente, mala salud subyacente, entre otras necesidades básicas. Las noticias de la ONU en agosto informaron que el Programa Mundial de Alimentos (PMA) se vio obligado a reducir su asistencia alimentaria y en efectivo para los refugiados en África oriental hasta en un $30 \%$, y se teme que las reducciones puedan empeorar en los próximos meses a menos que se reciba financiamiento adicional urgente (UN, 2020). Estas condiciones exacerban la transmisión del coronavirus, las enfermedades graves resultantes y la ausencia de tratamiento para las poblaciones desplazadas por la fuerza. En septiembre de 2020, ACNUR registró a 25.000 refugiados, otras personas desplazadas por la fuerza y apátridas infectadas con COVID-19 en 98 países, de los cuales 247 han muerto

Pero es la protección de los refugiados la que se ha visto socavada. Los cierres de fronteras y las restricciones a la movilidad internacional han impedido que los refugiados escapen de situaciones de persecución y el movimiento hacia lugares seguros. El acceso al asilo sigue siendo un derecho vital pero amenazado. Las medidas

4 Las vías complementarias de admisión son vías seguras y reguladas para los refugiados, que complementan el reasentamiento al proporcionar una estancia legal en un tercer país donde se satisfacen sus necesidades de protección internacional. Son adicionales al reasentamiento gubernamentales en varios países, en algunos casos respaldadas por la legislación, restringieron el acceso al país de refugiados y solicitantes de asilo. Las personas que llegan a las fronteras en busca de refugio seguro han sido devueltas a países vecinos, se les indica que soliciten asilo en consulados y embajadas o que esperen en otro lugar, a menudo de forma indefinida, para que se procesen las solicitudes.

Si conoce que en muchos países de Europa levantaron las restricciones de viaje y reabierto las fronteras para julio del 2020, pero la movilidad de los refugiados y solicitantes de asilo seguía obstaculizada. Las salidas de reasentamiento se detuvieron por primera vez en la historia y los procesos de visado para vías complementarias de admisión de refugiados ${ }^{4}$ se retrasaron significativamente. Por ejemplo, las personas en situaciones similares a las de los refugiados que transitan por el sudeste de Europa han experimentado prohibiciones de entrada en varios países. Se han reportado devoluciones en tierra y mar a lo largo de las fronteras entre Grecia y Turquía, así como en las fronteras de los países balcánicos y de Europa Central, África, Asia y Oriente Medio.

Si bien es cierto, los Estados tienen el deber soberano de proteger la salud pública, las medidas que restringen el acceso al asilo deben ser temporales, necesarias y proporcionadas. Así también, se debe respetar la prohibición de regresar a situaciones de persecución y peligro. La externalización puede corresponder a resguardar a los solicitantes de asilo indefinidamente en lugares aislados, "fuera de la vista y fuera de la mente", exponiéndolos al peligro y la devolución en cadena.

La salud y el bienestar de los refugiados, los desplazados internos, los apátridas y los solicitantes de asilo sigue siendo el segundo problema principal. La incapacidad para mantener incluso las condiciones higiénicas más

y no sustituyen a la protección brindada a los refugiados bajo el régimen de protección internacional. Estas vías incluyen la reunificación familiar, oportunidades de educación y empleo, patrocinio comunitario y visas y admisión humanitarias. 
básicas en los campos de refugiados en muchos lugares muy superpoblados, en particular los centros de recepción e identificación (RIC) en Europa, dio lugar a cuarentenas severas y prolongadas en esos campos y centros. En muchas instalaciones de campamentos de refugiados y desplazados internos prevalecen condiciones inadecuadas para la salud e higiene básicas, especialmente en África y Oriente Medio; esto sin considerar las medidas adicionales de enmascaramiento y distanciamiento. En varios países Los centros de detención de migrantes y refugiados también se han convertido en importantes focos de transmisión del coronavirus. Los desplazados internos y los apátridas enfrentan mayores desafíos para acceder a la atención médica debido a la falta de documentación, la falta de disponibilidad de servicios y la discriminación.

El desmejoramiento de las condiciones económicas locales y la nueva competencia por los recursos pueden exacerbar las tensiones entre las comunidades de acogida y desplazadas. Migrantes, refugiados, personas desplazadas y otros grupos marginados han sido acusados de propagar el virus desde el brote de la pandemia a principios de 2020 (Reuters, 2020; WHO, 2020).

Por otro lado, los mensajes xenófobos en las redes sociales, en las noticias o en el discurso oficial han provocado violencia y discriminación contra los no nacionales, incluidos incidentes de desalojo, denegación de servicios médicos o expulsión de hoteles (UNHCR, 2020b). En todo el mundo se informa de un aumento brusco y generalizado del discurso racista, xenófobo y de la violencia contra extranjeros, MRAA y desplazados internos en el contexto de COVID. (UNHCR, S.f. )

Adicionalmente, los servicios de atención médica no están disponibles, son inaccesibles o no existen en términos prácticos para los migrantes y refugiados en muchos lugares, incluso cuando tienen un estatus legal. La atención médica a menudo es inexistente o puede ser prohibitivamente costosa para quienes no residen legalmente en el territorio, quienes también pueden temer presentarse para someterse a pruebas o tratamiento debido al riesgo de detención o deportación. También, pueden tener dificultades para obtener información sobre riesgos y medidas de mitigación, debido a las barreras del idioma y al uso de medios de comunicación a los que no tienen acceso.

\section{Trabajadores móviles, transfronterizos y estacionales}

Millones de trabajadores móviles transfronterizos, estacionales y temporales se vieron inmediatamente afectados por los bloqueos y cierres de fronteras al comienzo de la pandemia. De igual manera las economías que dependen de esos trabajadores para la salud y otros servicios esenciales, la producción agrícola e industrial, el transporte, el comercio, el turismo y otras actividades. El resultado fue un gran costo para las economías locales que dependen de esa mano de obra. Así como también para el comercio transfronterizo de bienes y servicios proporcionados por esos trabajadores. En algunos casos, se negó a países enteros el suministro, en puntos de venta y distribución de la producción local y nacional, ya sea agrícola, artesanal o industrial. Esto incluye alimentos básicos, equipos de salud, medicamentos, suministros de consumos generales y otros bienes esenciales. Estos casos se dieron particularmente en áreas de comunidades económicas regionales (CER) en África central, oriental y occidental, en el área del mercado común de América del Sur MERCOSUR, en América Central, en la región del Caribe y el sudeste asiático. Fenómeno que se repite también en todos los países integrados en las economías de Europa dentro y fuera de la Unión Europea (UE) y las áreas de la Asociación Europea de Libre Comercio.

No obstante, en muchas fronteras se implementaron con relativa rapidez medidas de emergencia para permitir la movilidad de los "trabajadores esenciales". Esto logró garantizar que los trabajadores, indispensables para la agricultura, la producción, el procesamiento de alimentos, el transporte y de atención médica (entre ellos migrantes, trabajadores fronterizos, estacionales y del transporte) y la, pudieran cruzar las fronteras a pesar de cierres, confinamiento, medidas de "no viajar" o fronteras cerradas. 


\section{Países de origen}

Dentro de la tragedia pandémica del COVID 19, está el dilema que enfrentan millones de personas en los países de origen de los migrantes, quienes dependían de los ingresos y las remesas de los miembros de la familia de los trabajadores migrantes en el extranjero que quedaron desempleados y, en muchos casos, deportados a sus países de origen sin prácticamente ninguna posibilidad de reintegrarse en actividades remunerativas. Esto se ha agravado aún más por las percepciones locales del país de origen y de la comunidad de que los trabajadores migrantes que regresan a quienes miembros de sus propias familias y comunidades, los consideran como posibles portadores de COVID y deben mantenerse alejados (Asharq-Al-Awsat., 2020) .

Durante la primera ola, varios países de origen de trabajadores migrantes rechazaron el retorno o reingreso de sus propios ciudadanos, dejando a los expulsados o deportados de otros países en una situación casi apátrida y sus familias en la indigencia. Sin embargo, muchos países organizaron esfuerzos de repatriación, incluidos arreglos especiales de transporte para ciudadanos en el extranjero. La mayoría continúan permitiendo el reingreso de ciudadanos y residentes legales a pesar de los cierres de fronteras. No obstante, muchos de los países de origen de trabajadores migrantes en África, Asia y las Américas inicialmente tenían pocas o ninguna medida adecuada y apropiada para realizar pruebas, apoyar y asesorar a los repatriados a su llegada o después. También se permitió a los migrantes repatriados regresar a sus comunidades de origen cuando algunos eran, generalmente sin saberlo, portadores de coronavirus.

Los países de origen estuvieron durante mucho tiempo (algunos aún permanecen), sin planes y campañas adecuadas para la concienciación y la educación pública en las comunidades locales o de origen a las que los migrantes regresaban del extranjero. Muchos países de origen de trabajadores migrantes aún carecen de alimentos de emergencia y apoyo sanitario para las familias de migrantes que no tienen ingresos. Esta situación que se ve agravada cuando los migrantes que son el sostén de la familia regresan a casa (InfoMigrants/Deutsche-Welle, 2020).

\section{La necesidad de una acción parlamentaria urgente y apropiada}

A pesar de los enormes desafíos que enfrentan millones de trabajadores MRAA y desplazados internos en todo el mundo, la mayoría de las respuestas han sido unilaterales, nacionales, descoordinadas y, a menudo, contraproducentes. La coordinación, la cooperación y la acción común a nivel internacional han sido notoriamente débiles, lentas o inexistentes. No obstante, varias Comunidades Económicas Regionales (CER) se han comprometido en una movilización ejemplar de recursos, apoyo mutuo y acción común entre los países miembros. Esto con el estímulo de los parlamentos regionales, especialmente en la East Africa Community (Comunidad de África Oriental) (CAO) y otras comunidades regionales (EAC, 2020). Para el efecto, el Parlamento Europeo desde el principio alentó respuestas comunes y el mantenimiento de fronteras abiertas en la Unión Europea (UE) (European-Parliament, 2020).

Los desafíos y las líneas de respuesta se pueden clasificar en general en diez temas principales, reconociendo que los problemas se superponen y están interrelacionados. Así mismo se establece que una respuesta sostenible y eficaz requiere un enfoque integral con líneas de política y medidas de acción interdependientes en todos los temas. Ninguna solución rápida resolverá los complejos dilemas ni funcionará por sí sola de manera eficaz. Por lo contario, la búsqueda de soluciones rápidas desviará la atención de la obtención de apoyo político y público, así como de recursos para sostener el paquete de respuestas apropiado a nivel nacional y local que marcará la diferencia con el tiempo.

Las áreas temáticas como líneas de acción, sin un orden de jerarquía más allá del primero, son:

1) Salud, asistencia sanitaria, respeto del derecho a la salud y otros derechos relacionados.

2) Medidas de protección y apoyo comunitario. 
3) Inmigración, situación migratoria, administración de la ley y expedición de documentos de registro.

4) Movimiento a través de fronteras y no expulsión.

5) Retención de empleo, licencia temporal / suspensión / condiciones de despido.

6) Protección social y educación, incluso para las familias de los trabajadores migrantes despedidos / retornados.

7) Medidas específicas para refugiados, apátridas, desplazados internos y solicitantes de asilo.

8) Consideraciones específicas de género.

9) Comunicaciones, narrativa y no discriminación.

10) Recuperación, avanzando juntos.

Orientación a respuestas parlamentarias: acción, legislación y seguimiento

\section{Obligaciones normativas generales}

Los instrumentos internacionales de derechos humanos y las normas internacionales del trabajo (convenios y recomendaciones de la OIT) proporcionan la delimitación de derechos y responsabilidades imperativos para abordar el COVID-19. Se incluyen los derechos relacionados con la salud y la protección social. Muchos países han ratificado la mayoría de los nueve tratados internacionales fundamentales de derechos humanos (UN, S.f.). Además, todos los Estados miembros de la OIT están obligados a respetar los ocho convenios fundamentales de la OIT sobre no discriminación e igualdad de trato, abolición del trabajo forzoso, prevención de las peores formas de trabajo infantil y respeto por la libertad sindical y los derechos de negociación colectiva (ILO, 2021). Otras Normas Internacionales del Trabajo brindan orientación normativa sobre seguridad y salud en el trabajo, protección social y condiciones de trabajo decente. También se incluye normativas sobre el pago de salarios y beneficios a los trabajadores migrantes a su retorno o expulsión.

Adicionalmente, orientaciones normativas específicas para parlamentos, administraciones gubernamentales y otras partes interesadas respecto a refugiados, solicitantes de asilo y la prohibición de devolución, especialmente relevantes en este periodo de pandemia, son establecidas por la Convención de 1951 y el Protocolo de 1967 sobre el Estatuto de los Refugiados (UNHCR, 1951), y han sido ratificados por 160 países.

La Convención de 1954 sobre el Estatuto de los Apátridas y la Convención de 1961 para Reducir los Casos de Apatridia (UNHCR, s.f.), así como los Principios Rectores de los Desplazamientos Internos (UN, 2004), brindan también una orientación normativa adecuada para aquellos grupos especialmente en riesgo de exposición al COVID-19.

De manera similar, tres convenios internacionales proporcionan normas legales específicamente sobre migración para el empleo, derechos de los trabajadores migrantes y gobernanza de la migración (uno o más ratificados por casi 100 países). Se hace referencia a la Convención Internacional sobre la Protección de los Derechos de Todos los Trabajadores migratorios y de sus Familiares (ICRMW), 1990 (uno de los nueve instrumentos internacionales fundamentales de derechos humanos) (UN, 1990); la Convención de la OIT sobre las Migraciones para el Empleo (revisada), 1949 (No. 97) (ILO, 1949); y el Convenio sobre los Trabajadores Migrantes (disposiciones complementarias), 1975 (No.143) (ILO, 1975) . La Convención Internacional sobre la Protección de los Derechos de Todos los Trabajadores Migratorios y de sus Familiares proporciona una definición de trabajadores migratorios y miembros de su familia aplicable a la mayoría de los migrantes internacionales en todo el mundo. En ella se reconoce también a los trabajadores fronterizos, temporeros, móviles y otras categorías de trabajadores migrantes.

En resumen y considerando las normativas de derechos expuestas, se define que "Todas las personas en el territorio o bajo la jurisdicción de un Estado, independientemente de su nacionalidad o situación migratoria, tienen igual derecho a la salud. Los Estados tienen la obligación de garantizar el derecho a la salud de todas las personas sin discriminación, incluso por motivos de nacionalidad y situación migratoria. 
La escasez de recursos no es una base suficiente para tratar las necesidades de atención médica de los migrantes de manera diferente" (OHCHR, 2020).

Aunque no es legalmente vinculante, el Pacto Mundial sobre Refugiados, adoptado en diciembre de 2018 guía a la comunidad internacional en el apoyo a los refugiados, los países y las comunidades que los acogen mediante la movilización de la voluntad política, una amplia base de apoyo y activación de acuerdos para una distribución de responsabilidades más equitativa y predecible. Este consolida y actualiza las buenas prácticas y experiencias relevantes para la protección de refugiados, solicitantes de asilo, apátridas y desplazados internos, en el contexto del respeto e implementación de la Convención de 1951 y el Protocolo de 1967 sobre el Estatuto de los Refugiados (UN, 2018).

\section{Lista de verificación de pautas prácticas}

La lista de áreas temáticas como una guía de verificación resumida, proporciona líneas de política y acciones o pasos de acción basados en valores, ciencia y experiencia para parlamentarios y parlamentos sobre COVID-19 y migrantes y refugiados. Estas directrices se basan en lecciones de otras pandemias, en particular, el VIH y el SIDA, así como en otros conocimientos y experiencias, y consideran determinantes sociales, políticos, legales, ambientales y de salud.

No existen soluciones simples, pues se requiere un paquete completo de medidas, algunas de las cuales pueden lograrse mediante acciones administrativas. Sin embargo, todas necesitan supervisión parlamentaria, revisión, apoyo y habilitación legislativa, incluso asegurando que se disponga de recursos para incluir a MRAA y desplazados internos en las respuestas nacionales al COVID-19. En la siguiente sección se ofrecen ejemplos de parlamentarismos y acciones parlamentarias basada en la lista de las 10 áreas temáticas como guía.
Salud, asistencia sanitaria y respeto del derecho a la salud $y$ otros derechos relacionados (temática 1):

Las principales preocupaciones incluyen la exclusión extendida, a menudo generalizada, del acceso de los migrantes y refugiados a la atención médica preventiva, paliativa y curativa; en particular a la información confiable, pruebas, tratamiento y vacunación para COVID-19. También, la falta de provisión del adecuado, o cualquier otro, equipo de protección personal (EPP) para trabajadores migrantes en el ámbito sanitario, industrial, comercial o de otro tipo. Estos desafíos exacerban los riesgos de exposición y transmisión del coronavirus en las poblaciones de migrantes y refugiados, en los lugares de trabajo, en las comunidades y ciudades donde residen.

Las medidas de control de inmigración que buscan identificar y expulsar a personas en situaciones irregulares, incrementan los riesgos para la salud de la comunidad al conducir a los migrantes, solicitantes de asilo y apátridas en un contexto de «clandestinidad», disuadiéndolos de acceder a las pruebas COVID, al EPP, la vacunación y el tratamiento cuando sea necesario. Las principales líneas de respuestas apropiadas incluyen:

- Facilitar la integración de migrantes, refugiados, apátridas, desplazados internos y solicitantes de asilo en las pruebas, acciones de prevención y mitigación de COVID-19 locales y nacionales. vacunación y tratamiento.

- Eliminar las tarifas de las pruebas, vacunación y el tratamiento de COVID-19, independientemente de la ciudadanía, nacionalidad o estatus legal de migración/residente de la persona en el país.

- Brindar información sobre la prevención de la propagación, el diagnóstico temprano y el tratamiento de COVID-19 en idiomas que los migrantes, refugiados $\mathrm{y}$ otras personas desplazadas entiendan $\mathrm{y}$ en formatos accesibles. 
- Asegurar el acceso oportuno y efectivo a las instalaciones, bienes y servicios de salud para todos, independientemente de su estatus migratorio; mediante medidas legislativas, políticas, administrativas y prácticas, incluida la flexibilización de los requisitos de circulación y documentación.

- Crear / mantener una línea entre los servicios de salud e inmigración, permitiendo que apátridas, personas en riesgo de apatridia, migrantes en situaciones no autorizadas y otras personas accedan a los servicios sin la intimidación y disuasión al temor de ser identificados por las autoridades de control migratorio.

- Implementar medidas inmediatas para la protección y apoyo de los trabajadores migrantes en trabajos esenciales, especialmente aquellos relacionados con la salud y el cuidado; en particular, la capacitación en prevención y mitigación de riesgos, la provisión de EPP y protección de los espacios de trabajo.

- Asegurar la inclusión de migrantes, desplazados internos, apátridas, solicitantes de asilo y refugiados en igualdad de condiciones en la vacunación, distribución de productos de higiene, salud mental y apoyo psicosocial.

- Implementar programas de capacitación para profesionales de la salud buscando desarrollar habilidades básicas de ayuda psicosocial a personas afectadas directa o indirectamente por el COVID-19.

\section{Medidas de protección y apoyo comunitario (temática 2):}

Proporcionar medidas eficaces de prevención, protección y tratamiento del coronavirus es vital a nivel local y comunitario. Para el efecto se debe tener muy en cuenta: las condiciones de las localidades y las viviendas donde residen los migrantes y los solicitantes de asilo; situaciones de campamentos de refugiados y desplazados internos; y las circunstancias en las que una gran proporción de la población adulta depende del trabajo diario fuera de casa, cuando puede conseguirlo, para sobrevivir y alimentar a las familias. Es un hecho que el distanciamiento social es imposible y los bloqueos en el hogar son insuperables en muchas situaciones a las que se enfrentan los migrantes y refugiados, incluso en los países desarrollados. La falta de suministro lo cual incluye la imposibilidad de conseguir mascarillas, desinfectantes, y equipos de protección personal adecuados, hace inaccesible estos recursos para muchos. Además, la disponibilidad generalizada de vacunas a nivel mundial sigue muy lejos de las predicciones, y solo alcanzable durante el 2021 para las poblaciones de algunos países. Las medidas de respuesta urgentes incluyen:

- Determinar y aplicar medidas viables y apropiadas para el acceso al sustento $\mathrm{o}$ actividad remunerada en situaciones donde el distanciamiento social y el aislamiento son efectivamente imposibles, como viviendas hacinadas, barrios marginales, dormitorios de trabajadores migrantes y campamentos de refugiados.

- Implementar medidas de trabajo seguro en lugares de trabajo abarrotados que emplean a migrantes y personas desplazadas (por ejemplo, plantas empacadoras de carne, fábricas de confecciones), que de otro modo podrían ser puntos críticos de transmisión.

- Permitir la libre circulación con mascarillas, pautas de distanciamiento social y EPP, para quienes trabajan en la salud y otros empleos en localidades donde las personas y las economías dependen del trabajo diario para su sustento, especialmente donde el apoyo a las necesidades básicas no es factible o entregable debido a la ausencia de recursos, falta de infraestructura, gobernanza y otras instituciones débiles o ineficaces.

- Implementar medidas de compensación por pérdida de ingresos, bajo nivel de ingresos o recursos mínimos para mantener alimentos y viviendas esenciales para los migrantes, refugiados y otras personas desplazadas en el lugar. 
- Establecer e implementar medidas adecuadas para responder a los mayores riesgos de violencia, incluida la violencia de género, debido a la pandemia.

- Apoyar la participación de migrantes, refugiados y otras personas desplazadas en las respuestas al COVID-19, en particular profesionales, personal capacitado en atención médica y líderes comunitarios.

\section{Inmigración, situación migratoria, administración de la ley y emisión de documentos de registro (temática 3).}

Es fundamental proporcionar o mantener al menos un reconocimiento y estatus provisional a todos los migrantes y refugiados presentes en un país para garantizar que la información, la prevención, las pruebas, la vacunación y el tratamiento adecuados sobre el coronavirus lleguen a todas las personas de manera equitativa en cada comunidad y lugar. Se debe considerar que cualquiera que quede fuera es una probable víctima y vector del coronavirus. Las medidas imperativas para mantener la salud de las comunidades y los países, algunas implementadas en varios países incluyen:

- Prever medidas específicas para facilitar el ajuste de estatus, extensión temporal o renovación de permisos, y determinaciones o acciones grupales (como extensión de permisos para tipos de migrantes en lugar de procedimientos individuales) que permitan a los migrantes permanecer con estatus autorizado.

- Llevar a cabo la regularización de la situación de los migrantes para garantizar el reconocimiento legal, el acceso a servicios vitales y el empleo en situaciones regulares con protección de derechos y condiciones de trabajo decente.

- Garantizar la protección legal explícita de los derechos y la dignidad de los migrantes y refugiados durante las medidas de confinamiento obligatorio, así como las restricciones de viaje / circulación.
- Mantener el acceso irrestricto a los procedimientos de determinación y solicitud de asilo o refugio.

- Designar a los servicios de registro de nacimientos y defunciones como "servicios esenciales" y en funcionamiento para operar, con modificaciones temporales en los arreglos operativos según sea necesario y apropiado.

- Alentar a las autoridades a permitir la notificación y el registro en línea de eventos vitales, extender los plazos para el registro de nacimiento y establecer una exención de tarifas para el registro de nacimiento tardío.

- Promulgar reformas para defender el derecho de los ciudadanos a conferir la nacionalidad a los cónyuges e hijos y a adquirir, cambiar y conservar la nacionalidad en pie de igualdad, independientemente del género.

- Suspender toda detención de migrantes o solicitantes de asilo, no nacionales, excepto por violaciones criminales.

\section{Movimiento transfronterizo y no devolución (temática 4):}

El movimiento transfronterizo de trabajadores sigue siendo vital para mantener el suministro de alimentos, la atención de la salud, la producción agrícola e industrial y las economías en general en la mayoría de los países del mundo; particularmente en las comunidades económicas regionales y los mercados comunes. Por tanto, las medidas imperativas para mantener las economías y el bienestar local, nacional y regional, así como para garantizar el acceso al asilo y defender la protección de los refugiados, incluyen:

- Eliminar las barreras fronterizas que impiden el movimiento al trabajo de los trabajadores estacionales, fronterizos, temporales, desplazados, de transporte y otros trabajadores o empleados necesarios en las economías nacionales y transfronterizas, particularmente en los regímenes regionales de libre circulación. 
- Implementar medidas para mantener, restablecer y facilitar el movimiento a través de las fronteras, durante las medidas extraordinarias de restricción fronteriza. Las medidas para facilitar el movimiento de trabajadores a través de las fronteras se restablecieron rápidamente en varios países europeos, en Canadá, en África Oriental y en otros lugares, incluso en fronteras cerradas, para garantizar la movilidad transfronteriza esencial de los trabajadores, y de la movilización de bienes y servicios, como se expone en las iniciativas parlamentarias a continuación.

- Asegurar que el acceso a través de las fronteras nacionales para buscar protección de refugiados por parte de solicitantes de asilo y refugiados no se vea obstaculizado bajo la apariencia de restricciones de coronavirus, o por otras razones.

- Asegurar que los retornos se realicen de forma voluntaria, cumpliendo los requisitos de una decisión plenamente informada, sin coacción y respaldada por la disponibilidad de alternativas válidas.

- Asegurar que todos los retornos cumplan con el principio de no-devolución y la prohibición de expulsiones colectivas, así como las garantías del debido proceso, el acceso a abogados y traductores y el derecho a apelar, y que cualquier retorno sea compatible con el mantenimiento de la salud pública en el país de regreso.

\section{Retención laboral, baja temporal / suspensión / condiciones de despido (temática 5):}

Los despidos masivos de trabajadores, en particular migrantes, el cierre de empresas y fronteras y las deportaciones a gran escala como reacción a la pandemia COVID-19 han reducido la capacidad y competencia de toda la fuerza laboral, así como de sectores específicos en las economías locales y nacionales. Esto también condujo a una escasez generalizada temporal y a largo plazo de bienes y servicios, especialmente en el suministro de alimentos y la atención médica básica. La deportación o repatriación de un gran número de trabajadores migrantes de algunos países, comprometió gravemente la recuperación al eliminar la mano de obra y las habilidades necesarias para reconstruir la actividad económica y los negocios. Tomar medidas inmediatas es imperativo en muchos países para:

- Impedir el despido y la salida o deportación de los trabajadores necesarios para el trabajo esencial, así como la reanimación y recuperación económica.

- Establecer condiciones estrictas para los despidos y para la salida del país de empleo o regreso a la patria, incluido el período de notificación adecuado, el pago de todos los sueldos o salarios adeudados y la transferencia de las contribuciones y derechos de seguridad social devengados.

- Asegurar que los empleadores cumplan con todos los requisitos nacionales y locales de salud pública, seguridad y salud ocupacional y comunicar información crítica a los empleados, particularmente a los trabajadores (in) migrantes y refugiados.

- Evaluar en dónde se requiere la presencia y disponibilidad de trabajadores internacionales (en complementariedad con los trabajadores nativos) para mantener la actividad de producción y distribución, buscando a largo plazo, proporcionar innovación, habilidades necesarias y productividad en la fuerza laboral del país.

- Incluir obligatoriamente a empresarios migrantes, refugiados y otros desplazados en los incentivos económicos y el crédito proporcionado por el gobierno a las pequeñas y medianas empresas.

- Facilitar el movimiento y el reconocimiento de cualificaciones, particularmente para médicos y trabajadores de la salud refugiados y migrantes.

- Mantener los niveles de empleo y retener a los trabajadores y personas extranjeras con habilidades disponibles; las medidas pueden 
incluir reducción de horas sin despido y licencias temporales.

- Formular directrices y proporcionar incentivos para reanimar las economías locales y nacionales después de los cierres y durante los períodos de medidas especiales continuas; con la debida atención para asegurar que, se retenga o se le facilite el acceso a las personas con habilidades como mano de obra extranjera necesaria.

\section{Protección social y educación, incluidas las familias de los trabajadores migrantes despedidos/retornados (temática 6):}

La evidencia muestra que la protección social y el acceso a la educación se han visto devastados en todo el mundo como consecuencia no solo del coronavirus, sino también de las medidas restrictivas adoptadas para impedir su propagación. Los migrantes y refugiados se encuentran entre aquellos cuya protección social y educación se han visto socavadas de manera más devastadora. Las medidas urgentes específicas para garantizar la protección social y la escolarización de los migrantes y refugiados, y otros afectados de manera similar, incluyen:

- Garantizar el acceso a los servicios sociales, incluido el apoyo mental y psicosocial para todos, en particular niños, niñas y adolescentes y menores no acompañados $\mathrm{y}$ separados.

- Garantizar la prestación de atención médica básica y atención a todos los niños, incluidos los niños migrantes y desplazados, y los niños que permanecen "en casa" con sus padres en el extranjero.

- Proporcionar protección social a todos los migrantes y personas desplazadas.

- Establecer o mantener medidas de apoyo a las necesidades básicas especiales para las familias que no reciben el apoyo/sostén de los trabajadores migrantes en el extranjero.

- Extender paquetes de apoyo financiero a todos aquellos residentes en el territorio que cumplan con criterios de necesidades, riesgo o vulnerabilidad, independientemente de su estatus legal.

- Garantizar el acceso de todos los niños migrantes, refugiados, solicitantes de asilo, apátridas y desplazados a la escolarización con aprendizaje virtual, si el aprendizaje en el aula está restringido debido a las medidas contra el coronavirus. Incluso proporcionando dispositivos o alternativas a aquellos que no tienen conectividad de telecomunicaciones confiable, computadora personal, tabletas o hardware de teléfono celular.

- Proporcionar acceso continuo a refugios de emergencia para migrantes en tránsito, personas sin hogar y víctimas de desastres sin barreras en cuanto a su condición migratoria.

- Suspender los desalojos de viviendas y refugios.

Medidas específicas para refugiados, apátridas, desplazados internos $y$ solicitantes de asilo (temática 7):

Mantener la protección de los refugiados es fundamental en cualquier circunstancia, al igual que mantener los mecanismos de acceso para su protección y asistencia adecuada. Las precauciones para prevenir la propagación de COVID se pueden mantener o aplicar fácilmente sin obstaculizar el acceso a la protección, al reconocimiento legal y a situaciones de vida dignas para refugiados, solicitantes de asilo, apátridas y desplazados internos. Para el efecto se incluye:

- Mantener el acceso a la protección para refugiados, incluso garantizando el acceso al asilo, la evaluación individual, la evaluación y determinación del interés superior y la protección internacional en virtud de los derechos humanos internacionales y la ley de refugiados.

- Adaptar el registro y procesamiento de nuevas solicitudes de asilo por correo, o cualquier medio electrónico de comunicación. También, se debe hacer ajustes en las 
instalaciones y plataformas de comunicación de acuerdo con las pautas de salud pública, para que quienes buscan protección aún puedan hacerlo.

- Extender automáticamente los documentos de asilo y los plazos de registro civil, mientras los servicios están suspendidos y por un período razonable después de que los servicios de registro se hayan reiniciado, para permitir que las personas renueven sus documentos antes de que pierdan su validez.

- Facilitar los procedimientos de nacionalidad y cambiar las leyes y prácticas discriminatorias este sentido, particularmente aquellas que toleran la discriminación de género.

- Restablecer o permitir operaciones de rescate en el mar en la región del Mediterráneo, Asia meridional y otros lugares.

- Proporcionar acceso completo a la atención médica a los refugiados, desplazados internos y apátridas, incluyendo tratamientos, pruebas, prevención y vacunación contra el coronavirus, cuando estén disponibles, de manera similar a las poblaciones locales.

- Garantizar instalaciones sanitarias adecuadas, así como alimentos, agua, saneamiento e higiene para todas las personas desplazadas, en particular las que se encuentran en campamentos y centros de detención.

- Proporcionar espacios adecuados, reducir y prevenir el hacinamiento en los campamentos de refugiados y desplazados internos y centros de procesamiento. Si es necesario, ampliando las instalaciones o transfiriendo a los refugiados de instalaciones superpobladas a viviendas dignas, siempre que se respete la unidad familiar.

- Incluir a las personas desplazadas por la fuerza en los planes y programas nacionales de respuesta, así como en las redes de seguridad social y el apoyo en especie para responder al impacto socioeconómico de las pandemias.
- Abogar por la garantia de designaciones en locaciones adicionales al ACNUR y al PMA por parte del gobierno para permitir una vivienda o refugio decente y una nutrición adecuada para todos en los campamentos e instalaciones de refugiados y desplazados internos.

- Restablecer el reasentamiento, las vías complementarias y las operaciones y programas de reubicación regionales y nacionales.

\section{Consideraciones específicas de género (temática 8):}

El impacto del COVID, especialmente de las medidas de respuesta a menudo mal consideradas, ha tenido un marcado carácter de género, sobre todo para las mujeres y niñas migrantes y refugiadas. La epidemia paralela de violencia doméstica, el aumento de los embarazos de adolescentes, el aumento de la inaccesibilidad de la atención prenatal, del parto y posnatal por parte de los sistemas de salud abrumados por el COVID son sólo algunos de los desafíos que afectan particularmente a las mujeres refugiadas $y$ migrantes. Se necesita urgentemente un conjunto completo de medidas para:

- Asegurar que todos los esfuerzos de prevención y mitigación del COVID y la educación sean sensibles y apropiados al género.

- Abordar directamente los riesgos específicos para las mujeres migrantes y refugiadas, incluidas aquellas que trabajan en atención médica, el cuidado de personas mayores y otros trabajos esenciales.

- Fomentar las medidas de prevención y proporcionar EPP, llegando a las mujeres en el lugar de trabajo y en el hogar.

- Asegurar un alcance enfocado y dirigido para brindar información de salud, incluyendo específicamente información sobre el COVID, particularmente a mujeres y niñas migrantes, solicitantes de asilo, desplazadas 
internas, apátridas y refugiadas en situaciones aisladas de "difícil acceso".

- Garantizar que todas las mujeres embarazadas disfruten de manera adecuada y apropiada de una atención prenatal, durante el parto y posnatal. Para el efecto, se establece como deseable equipar a los proveedores de atención y las instalaciones de maternidad con material que permita a todas las mujeres embarazadas recibir atención y cuidados obstétricos requeridos. Sus cuidadores que deben usar mascarillas, otros EPP y un desinfectante apropiado.

- Mantener, o proporcionar, si no existe, información, servicios y productos de salud reproductiva, planificación familiar $\mathrm{y}$ anticonceptivos para todas las mujeres y niñas adolescentes refugiadas y migrantes.

- Reconocer, y proporcionar opciones de seguridad y refugios para las víctimas del aumento de la violencia doméstica contra mujeres y niños durante la pandemia, particularmente durante los encierros.

- Brindar acceso a productos de higiene menstrual, particularmente a mujeres y niñas en campamentos.

- Apoyar iniciativas de prevención y respuesta dirigidas a hombres y niños, destacando modelos masculinos positivos y promoviendo comportamientos no violentos.

- Apoyar servicios de atención telefónica de ayuda (call center), refugios, grupos de apoyo y otros mecanismos de solidaridad para mujeres migrantes y refugiadas.

- Promulgar reformas para defender el derecho de los ciudadanos a conferir la nacionalidad a los cónyuges e hijos ya adquirir, cambiar y conservar la nacionalidad en pie de igualdad, independientemente del género.

\section{Comunicaciones, narrativa y no discriminación (temática 9):}

Proporcionar información y conocimientos precisos y fiables que lleguen a todas las poblaciones e individuos es primordial para superar la pandemia y los efectos perjudiciales que ha generado la misma y muchas de las medidas de respuesta. Esto es especialmente crítico para superar la creciente desinformación y narrativas hostiles en torno al COVID-19, a los migrantes y refugiados y sobre las amalgamas entre la pandemia, la movilidad y la migración. La trasmisión de información precisa y narrativas de respeto y solidaridad es de hecho clave para lograr retroceder la discriminación, la exclusión y la violencia racista-xenófoba. Para el efecto se requiere:

- Articular y popularizar una narrativa de solidaridad, respeto e interés común con respecto a los migrantes, inmigrantes, refugiados, desplazados internos, apátridas y solicitantes de asilo.

- Enfatizar que los migrantes, refugiados y otras personas desplazadas son parte de nuestras comunidades y hacen contribuciones esenciales al bienestar económico y social de todos.

- Aclarar que la migración y la protección internacional de los refugiados no son factores de riesgo importantes para la transmisión internacional. Por lo contrario, los viajes -por negocios, turismo o vacaciones- no deben ser la principal preocupación puesto que la mayor parte de la transmisión es por exposición doméstica a la «comunidad». Los viajeros, los trabajadores del transporte, los trabajadores de temporada y los recién llegados pueden ser evaluados fácilmente antes del viaje o al llegar, si se asignan recursos.

- Especificar que la mayor parte de la transmisión fue, permanece y será «comunitaria» en todas partes.

- Reclamar medidas de protección básicas, igualdad de trato y comportamiento adecuado por parte de todos. 
- Adoptar medidas para prevenir, vigilar y abordar el racismo, la xenofobia, la discriminación, el odio y la violencia, incluida la responsabilización de los perpetradores.

- Apoyar las campañas de lucha contra la xenofobia y el racismo y garantizar que el discurso público y las respuestas al COVID19 no contribuyan a ello.

- Considerar las preferencias de ubicación, idioma y canal de comunicación de las personas desplazadas, en particular los apátridas y los desplazados internos, y promover esfuerzos de divulgación dedicados por parte de las autoridades pertinentes.

- Supervisar y corregir la circulación de información errónea, como medios de desinformación, incluso mediante la participación de líderes y miembros de la comunidad.

\section{Recuperación, Avanzando Juntos (temática 10)}

Si bien el fin de la pandemia y la recuperación social, del empleo y la movilidad en general no es inminente a nivel mundial, es oportuno prepararse para reconstruir juntos. Los principales desafíos incluyen la reducción del empleo y el estancamiento que se mantiene constante en los principales sectores económicos de muchos países. También, las fallas comerciales que aumentan especialmente entre las PYMES. Además, se prevé que se mantendrán los controles de la movilidad transfronteriza; que la situación socioeconómica de un gran número de personas empeorará si no se amplían los fondos de ayuda, expirándose las moratorias sobre los pagos de alquiler e hipotecas y las crisis de gobierno de varios países sigue sin resolverse. Por tanto, la recuperación sostenible y la reconstrucción de economías y sociedades necesariamente debe incluir:

- Fortalecer los servicios universales de calidad y la protección social disponibles, accesibles y con igualdad de trato para todos los migrantes y refugiados. Esto incluye explícitamente a todos los migrantes, refugiados, apátridas y personas desplazadas en la prevención, pruebas, EPP, vacunación y tratamiento del coronavirus. según sea necesario.

- Establecer la - Renta Básica Universal (RBU), con cobertura hacia todos los migrantes y refugiados residentes. Esta debe ser independientemente de su estatus, como la única forma viable de no dejar a nadie atrás, particularmente en el contexto del desempleo estructural generalmente agravado, los negocios acelerados y quiebras empresariales.

- Articular planes de recuperación ricos en empleo con medidas de apoyo al empleo inmediatas durante los períodos de bloqueo y durante la preparación para la recuperación sostenible, garantizando el acceso igualitario al empleo para los trabajadores migrantes y el apoyo a los empresarios migrantes y refugiados.

- Fortalecer la regulación, implementación, monitoreo y cumplimiento del trabajo decente y los derechos laborales, con inclusión explícita de la igualdad de trato / no discriminación en la ley, la aplicación de las normas laborales y la inspección del trabajo que cubra a todos los trabajadores migrantes.

Regular la situación de los migrantes en condiciones irregulares, reconociendo que la mayoría de ellos ingresan a los países de destino por medios regulares, aunque algunos exceden los permisos de estadía o acceden a un empleo sin autorización. Sin embargo, una gran proporción de los migrantes se encuentran dentro de espacios de libre circulación con derechos de movilidad, residencia y establecimiento.

\section{Resultados: ejemplos de acciones, iniciativas y legislaciones parlamentarias}

Reconociendo que es prematuro el poder constatar y evaluar resultados de un aproche aun 'en desarrollo', de cualquier manera, se presentan varios ejemplos de lo que algunos parlamentos han estado ejecutando, generalmente en 
conformidad con aspectos del modelo descrito arriba.

\section{Senado de Brasil: Proyecto de ley presentado sobre protección social para migrantes facilitado por la regularización de documentos}

Se presentó una propuesta legislativa en el Senado de Brasil en mayo de 2020 "para garantizar la igualdad de trato en la provisión de protección social y asistencia a los migrantes residentes en Brasil independientemente de su nacionalidad o situación migratoria, y que prevé el acceso acelerado de los migrantes a los servicios, ya sea mediante la regularización de documentos o adaptación a la documentación que posean los migrantes" (Gabrilli, 2020) ). Un gran impulso es eliminar los impedimentos burocráticos para el acceso de los migrantes a la asistencia y la protección sociales. Esto a menudo se debe a que su documentación no está acreditada, lo cual es un serio desafío para no dejar a nadie atrás, especialmente en tiempos de COVID. El proyecto de ley destaca las garantías de la Constitución Federal de igualdad de derechos bajo la ley para los extranjeros residentes en el país. Se incluye su relación con acceso libre e igualitario de los migrantes a programas y beneficios sociales, educación, asistencia jurídica pública, empleo, alojamiento, servicios bancarios y seguridad social. El proyecto de ley enfatiza las garantías de acceso a los servicios de salud pública y la providencia social sin discriminación de nacionalidad o condición migratoria, buscando su aplicación en la práctica.

\section{Resolución del Parlamento Europeo sobre la protección de los trabajadores estacionales y transfronterizos}

El Parlamento Europeo (PE) adoptó el 19 de junio del 2021 una Resolución sobre la protección de los trabajadores transfronterizos y estacionales en el contexto de la crisis del COVID-19. Se pedía una protección completa y estricta de sus derechos, el trabajo decente y las condiciones de vida en los 27 países miembros de la UE (European-Parliament, 2020). La resolución destaca que hay más de 17 millones de ciudadanos de la UE que viven y trabajan en el extranjero, en algún país de la UE distinto al de su ciudadanía (3,9\% de la población activa total en 2018); que hay alrededor de 1,5 millones de trabajadores transfronterizos en la UE; y que se generan más de 2,3 millones de operaciones de desplazamiento realizando servicios en otro Estado miembro. Se señala el severo impacto de COVID-19 en los viajes y las restricciones fronterizas sobre estos trabajadores, enfatiza el trabajo ya precario y desprotegido que enfrentan muchos. También se subraya el impacto del COVID en la salud de muchos de estos trabajadores en 'trabajo esencial'. La resolución pide a la Comisión que "emita nuevas directrices específicas para los trabajadores transfronterizos y estacionales, los empresarios transfronterizos y los autónomos, los empleadores y los Estados miembros en el contexto delo COVID-19. Específicamente en lo que respecta al ejercicio de la libre y justa circulación, vivienda digna, condiciones de trabajo y empleo aplicables, requisitos de salud y seguridad, la protección y coordinación de la seguridad social, el acceso y la provisión de atención médica, la provisión de información en el lugar de trabajo para los trabajadores en un idioma que puedan entender, y el intercambio de las mejores prácticas al respecto. Se subraya que los interlocutores sociales deben participar plenamente".

\section{Francia: El reclamo parlamentario por la regularización y la campaña de la sociedad civil}

En abril del 2020, 116 miembros, tanto del Senado Francés como de la Asamblea Nacional, firmaron una carta abierta al Primer Ministro pidiendo la regularización de los migrantes en situación irregular (Lambert, S.f.; Maxime, 2020). En junio del mismo año, una amplia coalición de organizaciones de la sociedad civil lanzó una campaña nacional de promoción para la regularización. La campaña envió una petición respaldada por cientos de organizaciones del país a todos los miembros del Parlamento Francés el 1 de julio del 2020 (Mediapart, 2020). La campaña subsecuentemente mantuvo el tema del trato a los migrantes y refugiados en la emergencia sanitaria (coronavirus) nacional en la agenda de la Asamblea Nacional y en la prensa nacional. 
Italia: regularización por parte del gobierno con impetu parlamentario.

Los partidos gobernantes de la coalición de Italia acordaron cambios en los permisos de trabajo para los migrantes en el país para beneficiar a los mismos y ayudar a los sectores afectados por el coronavirus. Una resolución parlamentaria enviada al gabinete en mayo de 2020 habilitó el decreto que permite la emisión de permisos de trabajo temporales a migrantes, incluidos muchos en situación irregular. La medida de regularización fue el resultado de negociaciones entre los cuatro partidos gobernantes de la coalición de Italia para apoyar al sector agrícola italiano, fuertemente afectado por las restricciones de viaje en tiempos del COVID-19 que impiden la llegada de trabajadores agrícolas de temporada contratados regularmente desde el extranjero (Sanderson, 2020). Los agricultores habían dicho que los cultivos se pudrirán en el suelo a menos que puedan atraer a más trabajadores. Se presentaron 80,366 solicitudes de regularización de migrantes en el primer mes del esquema, que comenzó el primero de junio del 2020 (ANSA, 2020).

Primer diálogo de presidentes de los Parlamentos Latinoamericanos: migrantes $y$ desigualdades sociales en la pandemia (Senado-de-la-República-de-Chile, 2020)

El primer Diálogo (virtual) de Presidentes de Parlamentos Latinoamericanos en octubre del 2020, se centró en la situación de los migrantes en las Américas y los desafíos para las políticas públicas, la salud y la protección social que plantea la pandemia COVID-19. Participaron 15 presidentes de los poderes legislativos de la región, convocados por el presidente de la Asamblea Nacional del Ecuador. También asistieron la presidenta de la Unión InterParlamentaria-UIP, la Secretaria General de la Organización de los Estados Americanos OEA, y la presidenta del - Parlamento Latinoamericano y del Caribe (Parlatino). Los participantes pidieron a los parlamentos nacionales que aboguen ante sus gobiernos por medidas que garanticen el retorno seguro de los migrantes a los países de origen.
Nueva Zelanda: Legislación para flexibilizar la ley y los procedimientos de inmigración: Ley de enmienda de inmigración (Respuesta COVID19) (Lees-Galloway, 2020)

El proyecto de ley, presentado en el Parlamento el 5 de mayo del 2020 y que obtuvo el consentimiento real el 15 de mayo, tenía como objetivo "garantizar que el Gobierno pueda responder de manera adecuada y eficiente al brote de COVID-19, proporcionando flexibilidad adicional en el sistema de inmigración".

Resolución 'Parliamentary Assembly of the Council of Europe:' consecuencias de la pandemia del COVID-19 para refugiados $y$ solicitantes de asilo

El Comité Permanente de la Asamblea Parlamentaria de los 47 países miembros del Consejo de Europa (CoE) adoptó una Resolución el 15 de octubre del 2020 subrayando que los solicitantes de asilo refugiados se vieron "doblemente afectados" por la pandemia de coronavirus.(Committee-on-InternationalAffairs-of-the-State-Duma, 2020)

El texto señaló que enfrentaban el cierre de fronteras, viajes más largos y peligrosos, mayores riesgos de retrocesos en el mar, períodos prolongados de detención con riesgo de propagación de epidemias, mayor violencia contra mujeres y niños, y una acumulación de solicitudes de asilo. La resolución instaba a los Estados miembros del CoE a mantener abiertas sus fronteras; levantar las restricciones de viaje innecesarias; garantizar el acceso al territorio mientras se protege la salud pública mediante exámenes médicos, pruebas y cuarentena. También incluye, adaptar las condiciones de acogida y evitar la detención; mantener sistemas de registro; seguir proporcionando vías para los procedimientos de asilo; "Mostrar una mayor solidaridad entre ellos"; y no utilizar a los migrantes como peones políticos deteniendo los rechazos, previniendo la violencia en las fronteras y asegurando que los "balseros" sean desembarcados rápidamente en los puertos. 


\section{ParlAmericas: Fortalecimiento de la supervisión de las respuestas a la pandemia COVID-19 (PalAmericas, 2020)}

ParlAmericas, la institución de Diplomacia Parlamentaria en el Sistema Interamericano, en agosto del 2020 realizó una reunión virtual para Reforzar la Supervisión de las Respuestas a la Pandemia COVID-19, auspiciada por la Cámara de Representantes de Uruguay. Se trata sobre desafíos y buenas prácticas del ejercicio de la fiscalización de las respuestas del gobierno a la pandemia del COVID-19. ParlAmericas incluye a las 35 legislaturas nacionales de América del Norte, Central y del Sur y el Caribe. Participaron 120 parlamentarios y personal de 17 países, identificando las Consideraciones Clave para la Supervisión Parlamentaria:

- Los comités parlamentarios juegan un papel importante en la práctica de la supervisión de las acciones gubernamentales.

- La vigilancia y la promoción son esenciales para garantizar que las respuestas reconozcan los impactos diferenciales de la pandemia en las mujeres, los hogares monoparentales, los trabajadores del sector informal y las poblaciones marginadas: indígenas, afrodescendientes, refugiados, desplazados internos, LGBTQ, personas sin hogar $\mathrm{y}$ prisioneros.

- La supervisión abarca el escrutinio de los presupuestos, la política fiscal y la asignación de recursos para el sector de la salud y también la inclusión de consideraciones de igualdad de género y clima en las respuestas de política.

- El doble desafío de los aumentos en el gasto público, y con frecuencia la deuda pública, junto con la caída de los ingresos requiere un escrutinio y reformas fiscales, incluidos regímenes fiscales más progresivos.

- La transparencia y la información son fundamentales para una supervisión eficaz por parte del poder legislativo y el público.
- Generar confianza pública en la respuesta y recuperación de la crisis socioeconómica y de salud, requiere una comunicación clara y oportuna con el público y su participación en la toma de decisiones.

\section{El Parlamento Portugués enmendó la Ley de Nacionalidad}

El Parlamento de Portugal adoptó en julio del 2020 una Enmienda a la Ley de Nacionalidad que permite el acceso a la ciudadanía a los hijos de migrantes o inmigrantes que hayan tenido un permiso de residencia y hayan vivido en Portugal durante un año (NIEM, 2020). Si bien sigue una tendencia en curso en la legislación portuguesa para permitir condiciones favorables para el acceso de inmigrantes al país, su aprobación en estos tiempos del COVID-19 reflejó una acción ejemplar por parte del Parlamento nacional a pesar de la pandemia.

\section{CONCLUSIONES}

Considerando las áreas temáticas como líneas de respuestas llamada a la necesidad de acción parlamentaria urgente y apropiada al problema del COVID-19 que enfrentan millones de trabajadores MRAA y desplazados internos en todo el mundo, se identifica que el principal desafío surge no solo de la pandemia en sí, sino también de las medidas de algunos gobiernos, empleadores y actores privados con respecto a esta población. Estos han incluido acciones basadas en el miedo y sin base científica, que han tenido consecuencias seriamente perjudiciales para las economías, las empresas, la salud, el bienestar y la cohesión social de comunidades y países enteros.

En general, los desafíos y las líneas de respuesta se pueden clasificar en diez temas principales, reconociendo que los problemas se superponen y están interrelacionados. Así también que una respuesta sostenible y eficaz requiere un enfoque integral con líneas de política y medidas de acción interdependientes en todos los temas.

Ninguna solución rápida resolverá los complejos dilemas ni funcionará por sí sola de 
manera eficaz. Por lo contario, la búsqueda de soluciones rápidas desviará la atención de la obtención de apoyo político y público, así como de recursos para sostener el paquete de respuestas apropiado a nivel nacional y local que marcará la diferencia en el tiempo.

Los gobiernos tienen una responsabilidad clave en dar respuestas y políticas de respuestas, coherentes, consistentes, comprehensivas, basadas sin excepción en la realización de los derechos humanos. Sólo un conjunto integral y multifacético de respuestas que aborden los diferentes problemas y preocupaciones interrelacionados puede resolver los desafíos sanitarios, económicos, sociales y políticos que plantea la pandemia de coronavirus en este mundo móvil, interconectado e interdependiente.

Por su lado, los parlamentos tienen la autoridad y la responsabilidad de abordar, dar forma $\mathrm{y}$ monitorear la acción gubernamental, o la inacción; así también, de apoyar las respuestas apropiadas de empleadores y empresas a través de acciones regulatorias e influir en los actores privados mediante el discurso y la legislación contra la discriminación e igualdad de trato.

Se enfatiza que una de las principales preocupaciones de la atención de la parte de gobiernos, de los parlamentaria nacional y regional, y también de las instancias de la sociedad civil es 'garantizar que las respuestas a la pandemia de coronavirus sean respetuosas hacia los derechos, apropiadas y proporcionales tanto para prevenir la propagación del coronavirus como para garantizar que los pueblos y las economías tengan la capacidad de mantener el bienestar nacional, comunitario e individual, anticipándose a la recuperación sostenible pero avanzando juntos'.

\section{AGRADECIMIENTOS}

Un sincero agradecimiento a Olga Kadysheva, Asociada de GMPA, por su constante apoyo en llevar a cabo esta investigación; a Kareen Jabre de la Unión Inter-Parlamentaria (UIP), a Ana Carolina Pinto Dantas y a Safak Pavey de la Oficina del Alto Comisionado de Naciones
Unidas para los Refugiados (ACNUR), por sus contribuciones editoriales a las versiones anterior de este manuscrito en idioma inglés. Un particular agradecimiento a UIP por su decidido apoyo, incluso financiero, que posibilitó el extenso trabajo de investigación permitiendo preparar este informe.

\section{REFERENCIAS}

ANSA. (2020). More than 80,000 applications for migrant regularization in Italy. [Artículo de prensa]. Francia. Obtenido de https://www.infomigrants.net/en/post/25791/mor e-than-80-000-applications-for-migrantregularization-in-italy

Asharq-Al-Awsat. (2020). Moroccan Immigrants Accused of Spreading Coronavirus in Their Country. Obtenido de https://english.aawsat.com//home/article/223312 6/moroccan-immigrants-accused-spreadingcoronavirus-their-country

Business-and-Human-Rights-Resource-Center. (2020). Uncertainty reigns in Qatar worker area sealed off over coronavirus fears. USA: BHRRC. Obtenido de https://www.businesshumanrights.org/en/latest-news/uncertaintyreigns-in-qatar-worker-area-sealed-off-overcoronavirus-fears/

Committee-on-International-Affairs-of-the-StateDuma. (2020). The COVID-19 pandemic has doubly affected migrants and refugees. Rusia: Comité de Asuntos Internacionales de la Duma Estatal. Obtenido de http://interkomitet.com/internationalparliamentary-organizations/pace/the-covid-19pandemic-has-doubly-affected-migrants-andrefugees/

EAC. (2020). East Africa Community COVID-19 Response Plan. Tanzania: EAC. Obtenido de https://www.tralac.org/documents/resources/covi d-19/regional/3466-eac-covid-19-response-planapril-2020/file.html

European-Parliament. (2020). European protection of cross-border and seasonal workers in the context of the COVID-19. Belgica: 
Parlamento Europeo. Obtenido de https://www.europarl.europa.eu/doceo/document /TA-9-2020-06-19_EN.html\#sdocta14

Global-Campaign. (2021). The Problem. USA: Global Campaign for Equal Nationality Rights. Obtenido de https://equalnationalityrights.org/the-issue/theproblem

Human-Rights-Watch. (2020a). Maldives: Covid19 Exposes Abuse of Migrants. USA: HRW. Obtenido de https://www.hrw.org/news/2020/08/25/maldivescovid-19-exposes-abuse-migrants

Human-Rights-Watch. (2020b). Yemen: Houthis Kill, Expel Ethiopian Migrants. USA: HRW. Obtenido de https://www.hrw.org/news/2020/08/13/yemenhouthis-kill-expel-ethiopian-migrants

Human-Rights-Watch. (2020c). Covid-19 Fueling Anti-Asian Racism and Xenophobia Worldwide. USA: HRW. Obtenido de https://www.hrw.org/news/2020/05/12/covid-19fueling-anti-asian-racism-and-xenophobiaworldwide

ILO. (1949). C097 - Migration for Employment Convention. Ginebra: Organización Internacional del Trabajo. Obtenido de https://www.ilo.org/dyn/normlex/en/f?p=NORM LEXPUB:12100:0::NO::P12100_INSTRUMEN T_ID:312242

ILO. (1975). C143 - Migrant Workers (Supplementary Provisions) Convention. Ginebra: Organización Internacional del Trabajo. Obtenido de https://www.ilo.org/dyn/normlex/en/f?p=NORM LEXPUB:12100:0::NO:12100:P12100_INSTRU MENT_ID:312288:NO

ILO. (2017). Promoting a Rights-based Approach to Migration, Health, and HIV and AIDS: A Framework for Action. Ginebra: Organización Internacional del Trabajo. Obtenido de https://www.ilo.org/wcmsp5/groups/public/--dgreports/--- gender/documents/publication/wcms_605763.pd $\mathrm{f}$

ILO. (2019). ILO global estimates on international migrant workers: results and methodology: International Labour Office. Ginebra: Organización Internacional del Trabajo. Obtenido https://www.ilo.org/wcmsp5/groups/public/--dgreports/---dcomm/---

publ/documents/publication/wcms_652029.pdf

ILO. (2021). Conventions and Recommendations. Ginebra: Organización Internacional del Trabajo. Obtenido de https://www.ilo.org/global/standards/introductio n-to-international-labour-standards/conventionsand-recommendations/lang--en/index.htm

InfoMigrants/Deutsche-Welle. (2020). Global poor hit as COVID-19 causes drop in remittances. Deutsche-Welle . Obtenido de https://www.infomigrants.net/en/post/27984/glob al-poor-hit-as-covid-19-causes-drop-inremittances

Lambert, F. (S.f.). Francois Michel Lambert interpelle le ler Ministre pour la regularisation provisoire des sans papiers. Obtenido de https://www.fmlambert.fr/Francois-MichelLambert-interpelle-le-1er-Ministre-pour-laregularisation-provisoire-des-sans-papiers-avec116_a1346.html

Lees-Galloway, I. (2020). Immigration (COVID19 Response) Amendment Bill. Wellington: Parlamento de Nueva Zelanda. Obtenido de https://www.parliament.nz/en/pb/bills-andlaws/bills-proposed-

laws/document/BILL_97675/immigration-covid19-response-amendment-bill

Maxime, G. (2020). Coronavirus. 104 parlementaires demandent la régularisation des sans-papiers, Actu Hauts-de-Seine. [Artículo de prensa]. Francia. Obtenido de https://actu.fr/societe/coronavirus/coronavirus104-parlementaires-demandent-regularisationsans-papiers_32993154.html 
Mediapart. (2020). Campagne collective nationale pour la régularisation - Courrier aux parlementaires. [Artículo de prensa]. Francia. Obtenido de https://blogs.mediapart.fr/pour-laregularisation-definitive-des-sans-

papiers/blog/020720/campagne-collectivenationale-pour-la-regularisation-courrie

NIEM. (2020). Parliament approved an amendment to Portugal's 'Law on Nationality'. Warsaw: NIEM. Obtenido de http://www.forintegration.eu/pl/parliamentapproved-an-amendment-to-portugal-s-law-onnationality

OHCHR. (2020). COVID-19 Guidance. fGinebra: Oficina del Alto Comisionado de Derechos Humanos. Obtenido de https://www.ohchr.org/EN/NewsEvents/Pages/C OVID19Guidance.aspx

PalAmericas. (2020). Strengthening Oversight of Responses to the COVID-19 Pandemic. Ontario: Secretaría Internacional de ParlAmericas. Obtenido de http://parlamericas.org/uploads/documents/Activ ity_Report_Oversight_ENG.pdf

Reuters. (2020). Malaysia rounds up migrants to contain coronavirus, U.N. warns of detention risks. Obtenido de

https://www.reuters.com/article/us-healthcoronavirus-malaysia-migrantsidUSKBN22E04A

Sanderson, S. (2020). Italy approves temporary changes to migrant work permits after weeks of political disagreement. [Artículo de prensa]. India. Obtenido de https://www.infomigrants.net/en/post/24720/italy -approves-temporary-changes-to-migrant-workpermits-after-weeks-of-political-disagreement

Senado-de-la-República-de-Chile. (2020). I Diálogo virtual entre Presidentes de los Poderes Legislativos de Latinoamérica: migrantes y desigualdad social preocupan en tiempos de pandemia. Valaparíso: Senado de la República de Chile. Obtenido de https://www.senado.cl/i- dialogo-virtual-entre-presidentes-de-los-podereslegislativos-de/senado/2020-06-08/205409.html

UN. (1990). International Convention on the Protection of the Rights of All Migrant Workers and Members of Their Families. Ginebra: Naciones Unidas. Obtenido de https://www.ohchr.org/EN/ProfessionalInterest/P ages/CMW.aspx

UN. (2004). Guiding principles on internal displacement. Ginebra: La Agencia de la ONU para los Refugiados. Obtenido de https://www.unhcr.org/protection/idps/43ce1cff2 /guiding-principles-internal-displacement.html

UN. (2018). Report of the United Nations High Commissioner for Refugees. Ginebra: Naciones Unidas. Obtenido de https://www.unhcr.org/gcr/GCR_English.pdf

UN. (2020). Refugees at risk of hunger and malnutrition, as relief hit in Eastern Africa [Refugiados en riesgo de hambre y mal nutrición, como golpe de socorro en África ], UN News. Ginebra: Naciones Unidas. Obtenido de https://www.google.com/search?gs_ssp=eJzj4tD P1Tcwy60qMGD04i4uzyypSi3KScxLAQBV2A fY\&q=switzerland\&rlz=1C1GCEV_en\&oq=swit $\&$ aqs $=$ chrome.2.69i57j0j46j0j69i60j69i6513.234 6j0j7\&sourceid $=$ chrome \&ie $=U T F-8$

UN. (S.f.). The Core International Human Rights Instruments and their monitoring bodies. Ginebra: Naciones Unidas. Obtenido de https://www.ohchr.org/EN/ProfessionalInterest/P ages/CoreInstruments.aspx

UNHCR. (1951). Convention and protocol relatingtothe status of refugees. Ginebra: La Agencia de la ONU para los Refugiados. Obtenido de https://www.unhcr.org/3b66c2aa10

UNHCR. (2020a). Refugee Data Finder. Ginebra: La Agencia de la ONU para los Refugiados. Obtenido de https://www.unhcr.org/refugeestatistics/

UNHCR. (2020b). Report on UNHCR's response to COVID-19 . Ginebra: La Agencia de la ONU 
para los Refugiados. Obtenido de

https://reporting.unhcr.org/sites/default/files/CO

VID-19\%20progress \%20report\%20-

$\% 2004.10 .20 \% 20-\% 20$ FINAL.pdf

UNHCR. (2021). Coronavirus Outbreak.

Ginebra: La Agencia de la ONU para los

Refugiados. Obtenido de

https://www.unhcr.org/coronavirus-covid-

19.html

UNHCR. (S.f. ). UN Conventions on Statelessness. Ginebra: La Agencia de la ONU para los Refugiados. Obtenido de https://www.unhcr.org/un-conventions-onstatelessness.html

WHO. (2020). A virus that respects no borders: protecting refugees and migrants during COVID19. Organización Mundial de la Salud. Obtenido de https://www.who.int/news-room/featurestories/detail/a-virus-that-respects-no-bordersprotecting-refugees-and-migrants-during-covid19 